\title{
Tensile strength of chorioretinal lesions produced by photocoagulation, diathermy, and cryopexy
}

\author{
H. ZAUBERMAN \\ From the Eye Department, Hadassah University Hospital, Jerusalem, Israel
}

Histopathological studies of chorioretinal lesions produced by the application of diathermy, cryopexy, and light coagulation indicate a sequence of chorioretinal reactions consisting of necrosis, exudate, and cellular infiltration, followed by pigment migration and proliferation, and finally by chorioretinal scar formation. The extent of the adhesion produced by these scars is only indirectly inferred from the histopathological appearance.

In a previous study (Zauberman and Berman, 1969), measurements were made of the adhesive forces between the normal sensory retina and the pigment epithelium in the cat's eye with the help of a modified analytical balance. Over the tapetum lucidum of freshly enucleated cat eyes, the weight needed to lift away the retina from the pigment epithelium varied between 60 and $90 \mathrm{mg}$. using $5 \mathrm{~mm}$.-wide strips of tissue. The same procedure was used in the present study to measure the tensile strength of chorioretinal lesions in the cat's eye over periods of time after the application of diathermy, cryopexy, and photocoagulation.

\section{Material and Methods}

Cats weighing between 2.5 and $3.5 \mathrm{~kg}$. were anaesthetized with an intraperitoneal injection of sodium pentobarbital. The pupils were dilated with I per cent. atropine, 0.25 per cent. scopolamine, and Io per cent. neosynephrine drops.

A linear incision was made in the skin extending from the outer canthus posteriorly for $5 \mathrm{~mm}$. The conjunctiva and Tenon's capsule were cut at a $5 \mathrm{~mm}$. distance from the limbus in the upper half of the globe. The bony orbit was partially removed with a rongeur in the upper temporal quadrant to obtain good exposure of the sclera beyond the equator. A 4/o silk suture was inserted in the upper temporal conjunctiva adjacent to the limbus and a tenotomy of the superior rectus muscle was performed. By exerting traction on the silk and pushing back the conjunctiva and Tenon's capsule, the sclera was well exposed in the upper temporal quadrant. A series of diathermic applications was made in the equatorial region in an area of $7 \mathrm{~mm}$. length by $5 \mathrm{~mm}$. width. The intensity of the application was controlled ophthalmoscopically until a moderate white reaction appeared in the fundus. Temporal to this area, two series of cryopexy and photocoagulation applications of similar ophthalmoscopic characteristics were performed.

The animals were killed 2, 7, 12, 1 7, 21, 35, and 96 days after application of the lesions, and the eyes were immediately enucleated. The anterior segment of each eye was excised. The lens and the vitreous were carefully removed, avoiding traction on the retina. Three 5 by $15 \mathrm{~mm}$. rectangular pieces of tissue consisting of sclera, choroid, and retina and containing the areas sub- 
mitted to diathermy, cryopexy, and photocoagulation, were cut out from each eye (Fig. I). The tissue strips were then pinned down at their corners to a soft rubber cushion, scleral side down, without piercing the retina. The traces of vitreous still adhering to the retina were then gently

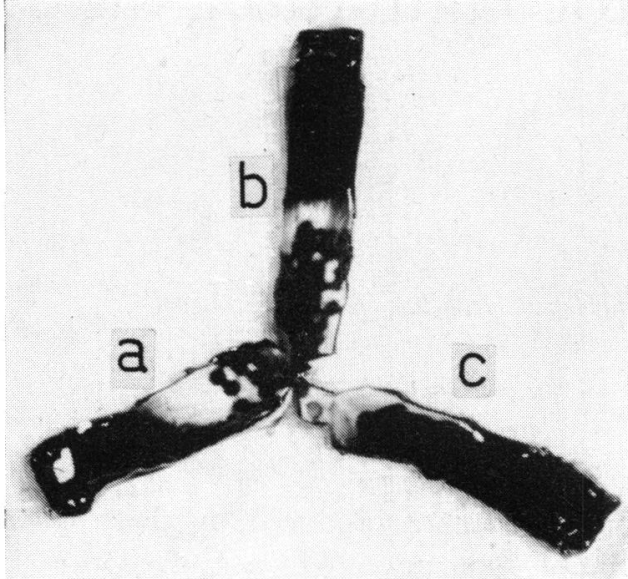

FIG. I Tissue appearance 21 days after application

(a) photocoagulation scars

(b) diathermy scars

(c) cryothermy scars

removed. A small segment of retina beyond the area submitted to treatment was lifted away with an iris repositor and tied with a 6/o silk suture which had a previously prepared loop at the other end. The tissue preparation together with the rubber cushion was then transferred to a deep Petri dish filled with normal saline. Measurements of the tensile strength of the chorioretinal lesions were made on a Sartorius digital analytical balance model 2403 , with a special hook-shaped counterweight which served to connect the silk attached to the retina to the balance. The tissue preparation was placed inside the weighing chamber of the balance on top of a small electrically-operated jack. The loop at the free end of the silk thread was attached to the counterweight and the instrument was balanced to the zero point. The thread was tensioned by starting the electric motor which lowered the jack at a constant speed of $0.5 \mathrm{~cm} . / \mathrm{min}$. As the retina was peeled away from the underlying tissue, readings were made simultaneously on the scale of the analytical balance of the adhesion of the normal retina and of the treated tissue to the underlying layers. Fig. $2(a-d)$ shows the gradual separation of the retina from the underlying layers.

(a)

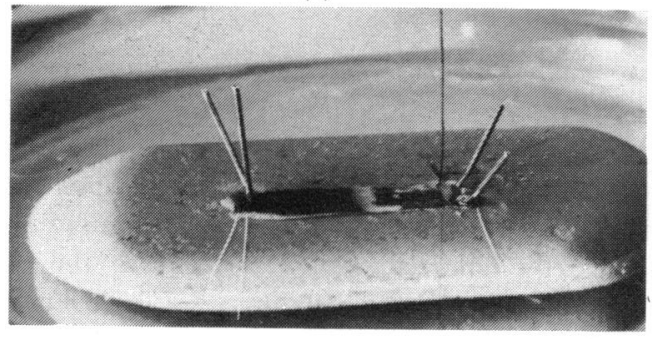

(c)

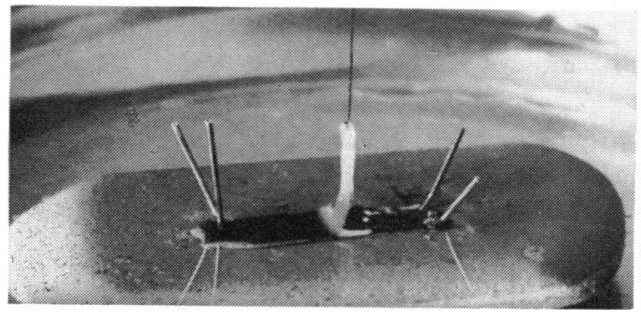

(b)

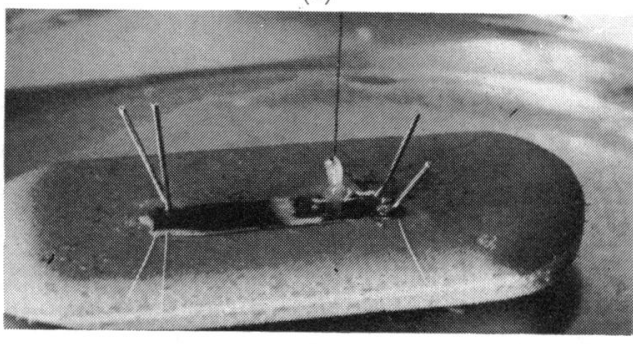

$(d)$

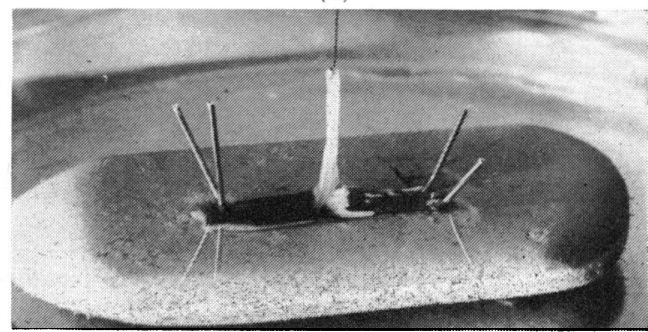

FIG. $2(a-d)$ Four stages of retinal separation from scars produced by diathermy $2 \mathrm{I}$ days after application 


\section{Results}

The extent of the attachment of the sensory cell layer of the retina to the pigment epithelium layer in the untreated areas over the tapetum lucidum varied between 55 and $80 \mathrm{mg}$. in the fourteen cats' eyes examined. These results corroborated those obtained in our previous study.

Over the areas of the fundus treated with cryopexy, diathermy, and photocoagulation, the measurements of the adhesions varied as a function of the time which had elapsed since the application of the procedures and to a much lesser degree as a function of the procedure used.

2 days after the application of cryopexy, diathermy, and photocoagulation, the weights necessary to lift up the retina over the tapetum lucidum ranged between 15 and $40 \mathrm{mg}$.

7 days after the application of any of the three procedures, weights between 65 and I $55 \mathrm{mg}$. were necessary to separate the retina. The Table shows that the adhesion progressively increased until the $2 \mathrm{Ist}$ day, when it reached values between 185 and $365 \mathrm{mg}$. for any of the three procedures. Thereafter, no significant increase was observed. The fluctuations in the weight needed to separate the retina from the underlying layers might well be due to the lack of homogeneity of the normal tissue and even more to differences in the treated areas.

Table Results obtained with treated and untreated retinal tissue

\begin{tabular}{llllll}
\hline \multirow{2}{*}{$\begin{array}{l}\text { No. of days after } \\
\text { application }\end{array}$} & Side & \multicolumn{2}{l}{ Tensile strength $(\mathrm{mg})}$. & \\
\cline { 2 - 6 } & & $\begin{array}{l}\text { Untreated } \\
\text { retina }\end{array}$ & Cryopexy & Diathermy & Photocoagulation \\
\hline 2 & Right & $50-80$ & $20-30$ & $30-40$ & $20-30$ \\
& Left & $60-75$ & $15-25$ & $30-40$ & $25-30$ \\
\hline 7 & Right & $55-80$ & $70-100$ & $95-130$ & $80-135$ \\
& Left & $50-70$ & $65-100$ & $100-155$ & $95-125$ \\
\hline 12 & Right & $60-75$ & $130-190$ & $150-210$ & $140-220$ \\
& Left & $55^{-80}$ & $145-200$ & $175-230$ & $180-240$ \\
\hline 17 & Right & $60-80$ & $200-300$ & $230-320$ & $250-340$ \\
& Left & $55^{-65}$ & $180-280$ & $180-280$ & $220-330$ \\
\hline 21 & Right & $65-85$ & $190-280$ & $240-315$ & $270-355$ \\
& Left & $55^{-70}$ & $185-275$ & $220-300$ & $275-365$ \\
\hline 35 & Right & $50-70$ & $180-285$ & $210-290$ & $260-345$ \\
& Left & $60-75$ & $175^{-280}$ & $250-310$ & $265-350$ \\
\hline 93 & Right & $50-80$ & $180-285$ & $250-310$ & $260-335$ \\
& Left & $60-85$ & $190-300$ & $255^{-295}$ & $280-370$ \\
\hline & & & & & \\
\hline
\end{tabular}

It should be noted that when attempts were made to separate the retina from the underlying layers in lesions 7 days old or more produced over the tapetum nigrum, the retinal tissue always tore before actual separation was achieved, indicating values higher than $45^{\circ}-600 \mathrm{mg}$., which is approximately the tensile strength of the $5 \mathrm{~mm}$.-wide retina (Zauberman and Berman, 1969).

Comparing the three procedures, the values were usually slightly higher for photocoagulation lesions than for diathermy or cryopexy, in that order. 


\section{Discussion}

Contrasting the strength of the chorioretinal lesions with the known histopathological findings (Lavyel, 1963; Curtin, Fujino, and Norton, 1965; Lincoff and McLean, 1965; $\stackrel{0}{\circ}$ Pannarale and Scullica, 1967) when both are assessed at a similar time after the application of any of the procedures used above, a good correlation is observed.

A decrease in the adhesive forces 2 days after treatment when chorioretinal oedema and $\frac{\widehat{Q}}{\varnothing}$ cellular infiltration were seen histopathologically was common to all three procedures. ळ

The tensile strength of the wound 7 days after the application was slightly higher than $\overrightarrow{0}$ in the untreated retina over the tapetum lucidum. Histopathological findings at this stage show pigmentary proliferative changes and pigment migration toward the outer $\stackrel{\sigma}{\omega}$ retinal layers. A gradual and progressive increase in tensile strength is observed between $\frac{0}{0}$. the 7 th and 2 Ist days, a period which shows histopathological changes consisting of $\mathcal{E}^{-}$ pigment migration into the inner retinal layers and scar formation. When the maximum adhesions produced by the three lesions were compared, it was found that they were slightly higher for photocoagulation than for diathermy, and for the latter than for cryopexy under the circumstances of these experiments.

The tensile strength of the scars over the tapetum lucidum 3 weeks after the application $\vec{z}$ of any of the three procedures became three to five times greater than that of the untreated areas. The clinical implications of these quantitative findings are that the 3 best time for a patient to resume his normal activities after detachment surgery is after $\stackrel{\oplus}{-}$ 3 weeks, when the adhesion between the retina and the underlying layers is strongest, and $\vec{\oplus}$ that it is probably not necessary to prolong his convalescence if the desired results have. 0 been obtained.

Danger of re-detachment is probably highest during the first week, when the adhesion is subnormal. Between the 8th and 2 rst days, the increasing tensile strength of the lesions diminishes the risk of re-detachment.

\section{Summary}

The tensile strength of chorioretinal lesions produced by photocoagulation, diathermy, and cryopexy over the tapetum lucidum of cats' eyes was measured with the help of ano analytical balance. Using $5 \mathrm{~mm}$.-wide strips of tissue, 2 days after these procedures:the adhesion was 15 to $40 \mathrm{mg}$., i.e. much lower than over the untreated areas.

From the 7 th to the 2 Ist day there was a gradual increase in the strength of the adhesion until it reached its maximum of 185 to $365 \mathrm{mg}$. Over the tapetum nigrum, the adhesion was much stronger, although no actual measurements could be performed because of the fragility of the retina, which tore before actual separation was achieved.

The adhesion was slightly stronger after photocoagulation than after diathermy and cryopexy in that order.

\section{References}

CURTIN, v. T., FUJINo, T., and NORTon, E. W. D. (1965) Arch. Ophthal. (Chicago), 75, 674

LAVYEL, A. (1963) Brit. F. Ophthal., 47, 577

LINCOFF, H. A., and MCLEAN, J. M. (1965) Ibid., 49, 337

pannarale, M. R., and sGullica, L. (1967) Boll. Oculist., 46, 947

ZAUBERman, H., and Berman, E. (1969) Exp. Eye Res., 8, 276 